\title{
Combination of multiple databases is necessary for a valid systematic review
}

\author{
Jia-Guo Zhao
}

Received: 17 September 2014 / Accepted: 23 September 2014 / Published online: 11 October 2014

(C) SICOT aisbl 2014

To the Editor,

Recently, we read with great interest the article by Jørgensen et al. [1] entitled "Predictors associated with nonunion and symptomatic malunion following non-operative treatment of displaced midshaft clavicle fractures - a systematic review of the literature" published online in International Orthopaedics. Jørgensen and colleagues performed a systematic review and only searched Medline up to September 2013. However, I think that Medline database alone cannot be enough for literature searches.

Systematic reviews are very important to health care practitioners, who need to keep abreast of the medical literature and make informed decisions. An inappropriate literature search is the major problem in systematic reviews, which can lead to an inaccurate estimation of effects. Relying exclusively on a Medline search may minimize relevant studies and maximize selection bias [2]. Prior studies [3-5] have demonstrated that a single search engine does not capture all of the pertinent and available articles, and using two or more databases provides greater coverage of all possible citations. For example, SuarezAlmazor et al. [2] found that the use of Medline alone to identify controlled clinical trials is inadequate because trials of methodological quality similar to those retrieved would be overlooked.

A comprehensive search is needed to locate large numbers of studies, which is necessary for a valid systematic review [6]. Based on the Cochrane Collaboration guidelines, a literature search should include all the articles matching the eligible criteria no matter the language, journal influence and sample size [7]. A comprehensive search should include multiple databases such as Medline, EMBASE, Cochrane Controlled Trials Register, Ovid, Google Scholar, and some specialty databases. Even some grey literature also should been considered to reduce the publication bias. Some websites such as World Health Organization International Clinical Trials Registry Platform and Current Controlled Trials, also should be searched for ongoing and recently completed studies.

In summary, systematic reviews use scientific methods to summarize results from multiple research studies. A combination of multiple databases would yield more articles than Medline alone, which can help us to make accurate decisions.

\section{References}

1. Jorgensen A, Troelsen A, Ban I (2014) Predictors associated with nonunion and symptomatic malunion following non-operative treatment of displaced midshaft clavicle fractures-a systematic review of the literature. Int Orthop. doi:10.1007/s00264-014-2450-7

2. Suarez-Almazor ME, Belseck E, Homik J, Dorgan M, Ramos-Remus C (2000) Identifying clinical trials in the medical literature with electronic databases: MEDLINE alone is not enough. Control Clin Trials 21:476-487

3. Zheng MH, Zhang X, Ye Q, Chen YP (2008) Searching additional databases except PubMed are necessary for a systematic review. Stroke 39:e139. doi:10.1161/STROKEAHA.107.524876

4. Brand-de Heer DL (2001) A comparison of the coverage of clinical medicine provided by PASCAL BIOMED and MEDLINE. Health Info Libr J 18:110-116

5. Woods D, Trewheellar K (1998) Medline and Embase complement each other in literature searches. BMJ 316:1166

6. Whiting P, Westwood M, Burke M, Sterne J, Glanville J (2008) Systematic reviews of test accuracy should search a range of databases to identify primary studies. J Clin Epidemiol 61:357-364. doi:10. 1016/j.jclinepi.2007.05.013

7. Higgins JPT (2011) GS Cochrane handbook for systematic reviews of interventions. Version 5.1.0 (updated March 2011). The Cochrane Collaboration, 2011. Available at: www.cochrane-handbook.org/. Accessed 17 September 2014
J.-G. Zhao $(\bowtie)$

Department of Orthopaedic Surgery, Tianjin Hospital, Tianjin, China e-mail: orthopaedic@163.com 